\title{
Tuleeko Suomesta vilja-aitta, kun ilmasto muuttuu?
}

\author{
Kaija Hakala ja Pirjo Peltonen-Sainio \\ MTT (Maa- ja elintarviketaluden tutkimuskeskus, Kasvintuotannon tutkimus, Kasvinviljely ja \\ teknologia, E-talo, 31600 Jokioinen. Sähköposti: kaija.hakala@mtt.fi, pirjo.peltonen-sainio@mtt.fi
}

\section{Tiivistelmä}

Suomen kasvintuotantoa rajoittaa lyhyt kasvukausi, matala kasvukauden lämpötila ja siten alhaiseksi jäävä lämpösumma. Ilmastonmuutoksen myötä koko maapallon ja myös Suomen keskilämpötila nousee. Suomelle tämä merkitsee kasvukauden pidentymistä ja lämpösumman nousua. Pidempi kasvukausi mahdollistaa satoisten pitkän kasvuajan lajikkeiden käyttöönoton Suomessa. Uusien kasvilajien ja -lajikkeiden myötä kasvintuotanto voi vähitellen tehostua. Myös ilman hiilidioksidipitoisuuden nousu lisää viljelykasvien fotosynteesiä ja satoa. Lisäys on suurinta kasveilla, joiden kehitys tuleentumista kohti ei etene tiukasti lämpösumman mukaan ja jotka voivat lisätä sadoksi kerättävää massaa rajatta. Tällaisia kasveja ovat esim. nurmet ja bioenergiakasvit sekä juurisatokasvit. Viljoilla kehityksen sitoutuminen lämpösummaan ja jyvän rajoitettu koko estävät hiilidioksidipitoisuuden nousun täyden hyödyntämisen.

Alkukesän kuivuus tulee olemaan ongelma myös tulevassa ilmastossa. Vaikka sademäärä keskimäärin nousee, suurin nousu tapahtuu kasvukauden ulkopuolella. Lisääntynyt haihdunta kohonneessa lämpötilassa, samoin kuin suuremmat satotasot vaativat kuitenkin entistä enemmän vettä. Syyskylvöisten ja monivuotisten kasvien paremmat viljelymahdollisuudet tulevaisuudessa helpottavat osaltaan kuivuusongelmaa, kun kasvit voivat käyttää hyväkseen talvisateiden tuomaa kosteutta alkukasvukaudella.

Lämpimämmät olot tuovat Suomen kasvintuotannolle myös erilaisia haittoja ja riskejä. Lämpimämmässä ilmastossa kasvitaudit ja tuholaiset tulevat mitä suurimmalla todennäköisyydellä lisääntymään, ja niiden torjuntakustannukset pienentävät sadonlisäyksen tuomaa taloudellista hyötyä. Myös maan mikrobitoiminta kiihtyy, jolloin vaarana on humuksen väheneminen ja ravinteiden lisääntynyt mineralisaatio ja huuhtoutuminen. Runsaammat talvisateet puolestaan edelleen lisäävät huuhtoutumisriskiä ja eroosiota. Monivuotisten runsasjuuristen kasvien viljely, pellon tiivistymisen välttäminen ja toimiva salaojitus vähentävät näitä riskejä.

Sääolojen kannalta Etelä-Suomesta saattaa lähivuosikymmeninä tulla nykyisen Tanskan veroinen maataloustuottaja. Suomen tulo osaksi Euroopan vilja-aittaa riippuu kuitenkin Suomen maatalouden sopeutumiskyvystä uudenlaisen ilmaston hyötyihin ja haittoihin, maailmankaupasta ja kasvintuotannon tuotteiden kysynnästä. Kasvintuotannon tuotteiden kysyntään vaikuttaa lähitulevaisuudessa vahvasti kasvintuotanto-olojen kehitys muualla maailmassa. Myös viimeaikainen bioenergiabuumi sekä elintason nousu runsaan väkiluvun alueilla, esim. Kiinassa ja Intiassa, lisäävät peltokasvituotannon ja maataloustuotteiden kysyntää ja hintaa ja siten tuotannon kannattavuutta. 


\begin{abstract}
Johdanto
IPCC:n 4 arviointiraportin mukaan (IPCC 2007a) maapallon keskilämpötila on viimeisten sadan vuoden aikana noussut noin yhden asteen. Nousun on tieteellisesti todettu olevan erittäin todennäköisesti seurausta ihmisen toiminnasta (IPCC 2007a). Koska kasvihuonekaasuja yhä edelleen päästetään ilmaan, lämpötila jatkaa nousuaan. IPCC:n keskiarvoskenaarioiden mukaan päästöt aiheuttavat $2^{\circ} \mathrm{C}$ nousun maapallon lämpötilassa seuraavan sadan vuoden aikana. Jos päästöt pystytään pitämään vuoden 2000 tasolla, ilman lämpötila nousee joka tapauksessa $0,3-0,9^{\circ} \mathrm{C}$ tämän vuosisadan loppuun mennessä. Rajoittamattomina jatkuvat päästöt aiheuttavat ennusteiden mukaan jopa $6^{\circ} \mathrm{C}$ lämpötilan nousun kuluvan vuosisadan loppuun mennessä verrattuna kauteen 1980-1999 (IPCC 2007a).

Maataloudelle lämpötilan noususta koituu sekä haittaa että hyötyä. Matalille leveysasteille ennustettu lisääntyvä kuivuus voi vaikeuttaa maataloutta vakavasti mm. Etelä-Euroopassa ja Välimeren alueella (IPCC 2007b). Toisaalta korkeilla leveysasteilla kuten Suomessa lämpötilan nousu voi hyödyttää maanviljelyä mm. pidemmän kasvukauden ansiosta (IPCC 2007b). Jo nyt viljelijät ovat alkaneet kokeilla perinteisten Keski-Euroopan lajien ja lajikkeiden, kuten rapsin ja rehumaissin viljelyä, jotka ovatkin 2000-luvun lämpimissä kasvukausissa menestyneet odotettua paremmin. Ilmatieteen laitoksen ja MTT:n laskelmien perusteella esim. rapsin tuotantovarmuus ja kilpailukyky rypsiin nähden paranee huomattavasti jo lähimpinä vuosikymmeninä (www.mtt.fi/rypsirapsi, Peltonen-Sainio ym. 2008a). Todennäköistä on, että monien muidenkin kasvilajien ja -lajikkeiden menestymisen edellytykset paranevat Suomessa ilmaston lämmetessä. Toisaalta taudit, tuholaiset ja maan rakenneongelmat saattavat haitata maataloustuotantoa. Nyt esiteltävässä tutkimuksessa käytettiin Ilmatieteen laitoksen ILMASOPU-projektille (www.mtt.fi, palvelut-tiedonhaku-hanska-ilmasopu) laatimia lämpötila- ja sade-ennusteita tulevaisuuden ilmaston hahmottamiseksi eri aikakausina kolmella Suomen paikkakunnalla. Tuloksia verrattiin nyt vallitseviin oloihin Tanskassa ja Hollannissa verraten samalla Tanskan ja Hollannin maatalouden tuotantolukuja Suomen vastaaviin.
\end{abstract}

\title{
Aineisto ja menetelmät
}

Ilmatieteen laitos laski ILMASOPU-projektissa Suomelle lämpötila- ja sademääräskenaariot kausille 2010-2039, 2040-2069 ja 2070-2099, keskiarvovuosina 2025, 2055 ja 2085. Laskelmat tehtiin sekä vahvan kasvihuonekaasupäästöjen hillinnän (B1) että jatkuvien päästöjen (A2) tilanteessa (IPCC 2000). Nyt esiteltävät tulokset on laskettu A2-skenaarioiden pohjalta. Tulevaisuuden tilanteen havainnollistamiseksi Suomessa valittiin kolme paikkakuntaa: Etelä-Suomen Jokioinen, Pohjanmaan Seinäjoki ja Koillis-Suomen Kajaani, joille laskettiin sekä lämpötilaan perustuvia kasvukauden tunnuslukuja että vuoden keskimääräiset sadanta-arviot kaudelle 1971-2000 (keskiarvovuosi 1986) sekä vuosille 2025 (2010-2039), 2055 (2040-2069) ja 2085 (2070-2099). Lisäksi kirjallisuudesta (Tveito ym. 2001) ja internetistä (European Climate Assessment \& Dataset, Koninklijk Nederlands Meteorologisch Instituut, http://eca.knmi.nl, 17.11.2007) etsittiin säätilastoja Tanskan sekä Pohjois- ja Etelä-Hollannin osalta. Saatuja arvoja tarkasteltiin yhdessä Suomen, Tanskan ja Hollannin maatalouden tuotantolukujen kanssa (FAOSTAT, 13.9.2007, keskiarvot vuosilta 2001-2006).

\section{Tulokset ja tulosten tarkastelu}

\section{Nyky-Suomi häviää reippaasti satotasojen vertailun jo pohjoisen Euroopankin kanssa}

Suomen, Tanskan ja Hollannin hehtaarisatoja eri kasveista on esitetty Taulukossa 1. Suomen sadot ovat 35-60\% matalampia kuin Tanskan ja Hollannin sadot. Suurin ero (60\%) on rypsin (Hollannissa ja Tanskassa rapsi) ja seuraavaksi suurin (50-60\%) vehnän sadoissa. Myös rukiin sato Suomessa on alle puolet Tanskan ja Hollannin sadosta. Lisäksi Hollannissa ja Tanskassa viljellään menestyksellisesti rehumaissia ja ruisvehnää, joiden viljelyä Suomessa on vasta kokeiltu. 
Taulukko 1. Tavallisimpien viljelykasvien hehtaarisatoja $\left(\mathrm{kg} \mathrm{ha}^{-1}\right)$ Suomessa, Tanskassa ja Hollannissa. Keskiarvo sadoista vuosilta 2001-2006. Rypsiä viljellään vain Suomessa; Tanskassa ja Hollannissa viljellään rapsia (FAOSTAT 13.9.2007).

$\begin{array}{llll} & \text { Suomi } & \text { Tanska } & \text { Hollanti } \\ \text { Ohra } & 3347 & 5166 & 5975 \\ \text { Maissi (rehu) } & ----- & 35457 & 41420 \\ \text { Kaura } & 3090 & 4764 & 5163 \\ \text { Ruis } & 2322 & 4890 & 4758 \\ \text { Ruisvehnä } & ----- & 4810 & 5130 \\ \text { Vehnä } & 3492 & 7139 & 8437 \\ \text { Rypsi/Rapsi } & 1337 & 3162 & 3763 \\ \text { Herneet } & 2192 & 3522 & 4529 \\ \text { Peruna } & 23511 & 38971 & 43258 \\ \text { Sokerijuurikas } & 35721 & 57439 & 61303\end{array}$

\section{Ilmastonmuutos pidentää kasvukautta ja lisää lämpösummaa Suomessa parantaen} kasvintuotannon edellytyksiä

Kasvukautta ja ilmastoa kuvaavat tunnusluvut selittävät omalta osaltaan suuria satoeroja (Taulukko 2). Suomen kasvukausi on tällä hetkellä vähintään 50 vrk lyhempi kuin Tanskan, ja lämpösumma on 200400 astetta pienempi. Pohjois-Hollantiin verrattuna eroa on vähän enemmän, Etelä-Hollantiin verrattuna Suomen kasvukausi on jopa 100 vrk lyhempi ja lämpösumma vähintään 700 astetta pienempi. Suurin ero on talvipäivien (päiviä, joiden keskilämpötila on alle $0^{\circ} \mathrm{C}$ ) lukumäärässä, joka Suomessa on yli 125, Tanskassa 1-25 ja Hollannissa 0-2 (Taulukko 2).

Taulukko 2. Suomen ja Tanskan (Tveito ja muut 2001) sekä Hollannin (European Climate Assessment \& Dataset, Koninklijk Nederlands Meteorologisch Instituut, http://eca.knmi.nl, 17.11.2007) ilmasto- ja kasvukauden tunnuslukuja jaksolta 1960-1990. Lämpösummat on laskettu yli $5^{\circ} \mathrm{C}$ lämpötilan pohjalta. ${ }^{1)}$ Jokioinen, ${ }^{2)}$ Seinäjoki ja Kajaani. Hollannin tunnusluvut on laskettu 30 vuoden keskiarvoista kahdelta paikkakunnalta, Groningen (Hollanti N) ja Eindhoven (Hollanti S).

\begin{tabular}{|c|c|c|c|c|c|}
\hline & $\begin{array}{l}\text { kasvukauden } \\
\text { alku }\end{array}$ & $\begin{array}{l}\text { kasvukauden } \\
\text { loppu }\end{array}$ & $\begin{array}{l}\text { pv yli } 5^{\circ} \mathrm{C} \\
\text { (kasvuk. } \\
\text { pituus) }\end{array}$ & $\begin{array}{l}\text { pv alle } 0^{\circ} \mathrm{C} \\
\text { (talven } \\
\text { pituus) }\end{array}$ & $\begin{array}{l}\text { kasvukauden } \\
\text { lämpösumma }\end{array}$ \\
\hline Suomi & $\begin{array}{l}\text { 16-30.huhti }{ }^{1)} \\
1-15 . \text { touko }^{2)}\end{array}$ & 1-15.loka & $150-175$ & $\begin{array}{l}125-150^{1)} \\
150-200^{2)}\end{array}$ & $1000-1200$ \\
\hline Tanska & 1-15.huhti & 1-15.marras & $>225$ & $1-25$ & $1400-1600$ \\
\hline Hollanti N & 24.maalis & 19.marras & 231 & 2 & 1667 \\
\hline Hollanti S & 10.maalis & 26.marras & 252 & 0 & 1907 \\
\hline
\end{tabular}

Ilmaston lämmetessä Suomenkin kasvuolot muodostuvat edullisemmiksi ainakin lämpötilan ja kasvukauden pituuden osalta. Kasvukauden tunnuslukujen muutoksia ilmaston muuttuessa on esitetty kolmelta Suomen paikkakunnalta (Jokioinen, Seinäjoki ja Kajaani) Taulukossa 3. Nykyisen Tanskan tyyppinen ilmasto nyt valittujen tunnuslukujen osalta näyttäisi vallitsevan kaudella 2070-2099 (keskiarvovuosi 2085) Jokioisilla ja Seinäjoella, mutta ei Kajaanissa. Etelä-Suomessa (Jokioinen) lämpösumma voi nousta Tanskan nykyiselle tasolle jo aiemmin (keskiarvovuosi 2055), mutta talvipäivien määrä on selvästi Tanskan arvoa isompi ja kasvukausi lyhempi. Nykyisen Etelä-Hollannin tyyppiseen ilmastoon eivät ainakaan nyt tutkitut kolme Suomen paikkakuntaa pääse lähimmän sadan vuoden kuluessa ellei ilmastonmuutos kiihdy huomattavasti. Vaikka kasvukausi Jokioisilla ja 
Seinäjolla näyttäisi saavuttavan Tanskan nykyisen kasvukauden pituuden arviointikaudella 2070-2099, osa siitä voi pitkän talven vuoksi jäädä hyödyntämättä keväällä maan märkyyden ja siitä johtuvan rakenteen heikkouden takia ja syksyllä valon määrän vähyyden vuoksi. Samalla myös osa kasvukauden lämpösummasta jää hyödyntämättä. Onkin mahdollista, että peltoviljelykausi Suomen oloissa ei pitene samaan tahtiin kasvukauden kanssa, vaan jää edelleen huomattavasti lyhemmäksi kuin esim. nykyisessä Tanskassa (Peltonen-Sainio ym. 2008b). Näin ollen mitä todennäköisimmin Suomi ei pääse nykyisiin Tanskan tuotantolukuihin vielä lähimpään sataan vuoteen, jos katsotaan pelkästään hehtaarisatoja. Kun viljely kuitenkin jatkossa ilmaston lämmetessä voi laajeta Suomessa uusille alueille ja nykyisillä alueilla viljely tehostuu (Carter ja muut 1995), kokonaistuotanto Suomessa mitä todennäköisimmin kasvaa merkittävästi ilmastonmuutoksen edetessä.

Taulukko 3. Suomen ilmaston tunnuslukuja kaudella 1971-2000 (keskiarvovuosi 2086) ja tulevaisuuden skenaarioita A2-skenaarion mukaan laskettuna kausille 2010-2039 (2025), 2040-2069 (2055) ja 2070-2099 (2085). Tunnusluvut on laskettu Ilmatieteen laitoksen ILMASOPU-projektille laskeman datan perusteella. Paikkakuntien arvot ovat lähimmän dataruudun arvoja (ruudun koordinaatit suluissa).

\begin{tabular}{|c|c|c|c|c|c|}
\hline $\begin{array}{l}\text { Jokioinen } \\
\left(60.75^{\circ} \mathrm{N}, 23.75^{\circ} \mathrm{E}\right)\end{array}$ & kasvuk alku & kasvuk. loppu & pv yli $5^{\circ} \mathrm{C}$ & pv alle $0^{\circ} \mathrm{C}$ & lämpösumma \\
\hline 1986 & 27.huhti & 12.loka & 169 & 139 & 1193 \\
\hline 2025 & 22.huhti & 18.loka & 181 & 121 & 1371 \\
\hline 2055 & 16.huhti & 28.loka & 196 & 93 & 1577 \\
\hline $\begin{array}{l}2085 \\
\text { Seinäjoki } \\
\left(62.75^{\circ} \mathrm{N}, 22.75^{\circ} \mathrm{E}\right.\end{array}$ & 5.huhti & 9.marras & 219 & 27 & 1859 \\
\hline 1986 & 30.huhti & 6.loka & 160 & 149 & 1082 \\
\hline 2025 & 25.huhti & 12.loka & 171 & 131 & 1248 \\
\hline 2055 & 18.huhti & 21.loka & 186 & 106 & 1436 \\
\hline $\begin{array}{l}2085 \\
\text { Kajaani } \\
\left(64.25^{\circ} \mathrm{N}, 27.75^{\circ} \mathrm{E}\right)\end{array}$ & 8.huhti & 3.marras & 208 & 34 & 1708 \\
\hline 1986 & 7.touko & 25.syys & 142 & 169 & 958 \\
\hline 2025 & 2.touko & 3.loka & 155 & 156 & 1117 \\
\hline 2055 & 27.touko & 10.loka & 167 & 136 & 1300 \\
\hline 2085 & 19.huhti & 21.loka & 186 & 99 & 1546 \\
\hline
\end{tabular}

\section{Kuivuus voi olla ongelma, vaikka sademäärä kasvaisikin}

Sademäärä lisääntyy keskimäärin korkeilla ja vähenee matalilla leveysasteilla ilmastonmuutoksen edetessä (IPCC 2007a). Vaikka siis Suomessakin sademäärä lisääntyy, se lisääntyy eniten talvella ja syksyllä. Esim. Jokioisilla kevään (maalis-toukokuu) sateet lisääntyvät keskimäärin vain $4 \mathrm{~mm} / \mathrm{kk}$ ja kesäsateetkin (kesä-heinä-elokuu) vain $6 \mathrm{~mm} / \mathrm{kk}$ vuoteen 2085 mennessä, kun talvi- ja syyssateet (syyskuukuu-helmikuu) lisääntyvät $10 \mathrm{~mm} / \mathrm{kk}$ (Kuva 1). Kevätkuivuuteen ei näin ollen ole tulossa helpotusta. Kesänkään vesitilanne ei lisääntyneestä sademäärästä huolimatta sanottavasti parane, koska lämpötila ja haihdutus lämpimämmässä ilmastossa vastaavasti nousevat, ja kasvavan satopotentiaalin vuoksi kasvustot myös tarvitsevat enemmän vettä. Kevätkylvöisillä viljelykasveilla alkukasvukauden kuivuus voi haitata yhä vakavammin kasvintuotantoa. Syyskylvöisillä kasveilla tilanne on parempi, koska ne voivat hyödyntää talven mittaan maahan kertynyttä kosteutta keväällä ja alkukesästä. 

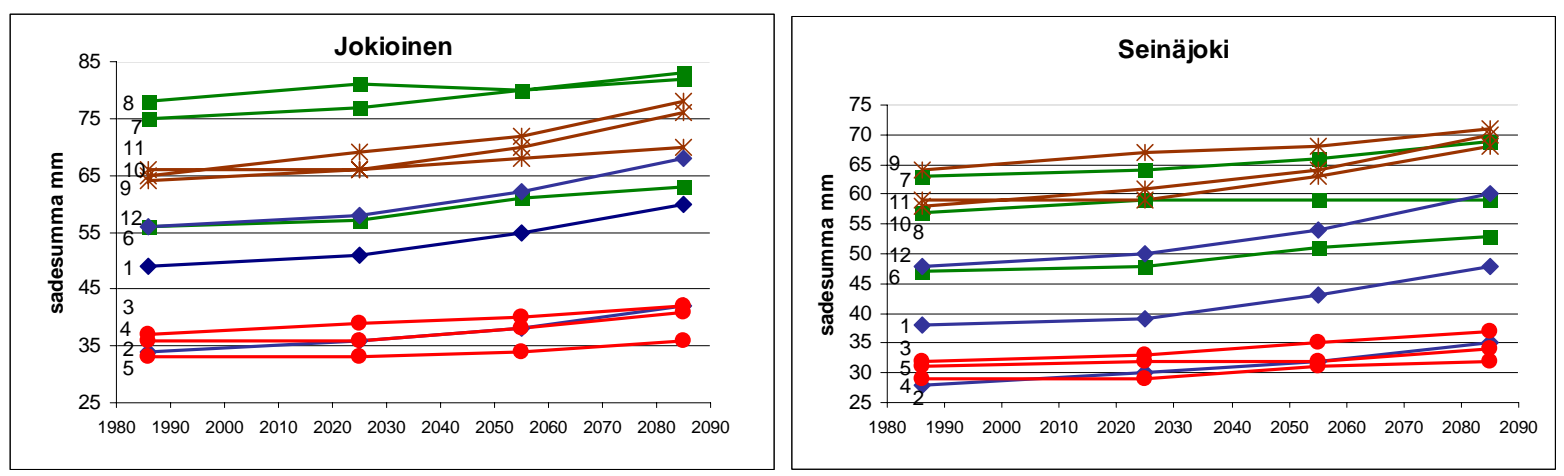

Kuva 1. Sadanta kuukausittain nyt (vuosi 1986, keskiarvo kaudesta 1971-2000) ja keskiarvovuosina 2025 (20102039), 2055 (2040-2069) ja 2085 (2070-2099) Jokioisilla ja Seinäjoella. Kuvat on piirretty Ilmatieteen laitoksen ILMASOPU-projektille A2-skenaarion mukaan laskeman datan perusteella. Punaiset käyrät (pallot): kevät (maalis-toukokuu), vihreät käyrät (neliöt): kesä (kesä-elokuu), ruskeat käyrät (tähti): syksy (syys-marraskuu), siniset käyrät (salmiakki): talvi (joulu-helmikuu). Käyrien alussa myös kuukausien numerot.

\section{Hiilidioksidin lisääntyminen tehostaa fotosynteesiä ja nostaa satoa}

Hiilidioksidipäästöt ovat merkittävä ilmaston lämpenemisen moottori ja syynä moniin tulevaisuuden haasteisiin, jopa ongelmiin globaalissa kasvintuotannossa. Kohonnut ilman hiilidioksidipitoisuus sinänsä kuitenkin hyödyttää kasveja monin tavoin. Kasvit yhteyttävät auringonvalon avulla ilman hiilidioksidia, ja mitä enemmän hiilidioksidia on ilmassa, sitä tehokkaampaa yhteyttäminen on. Korkeassa hiilidioksidipitoisuudessa kasvilla on myös varaa sulkea ilmarakojaan hiukan, mikä vähentää haihdutusta ja siten parantaa kasvin vesitaloutta. Toisaalta haihdutuksen viilentävä vaikutus vähenee ja lehden lämpötila nousee. Tämä yhdessä ilman lämpötilan nousun kanssa nopeuttaa etenkin päättyväkasvuisten viljojen kehitystä ja vähentää niiden satoja. Tutkimuksissa on kuitenkin käynyt ilmi, että kohonneen hiilidioksidin vaikutus kompensoi kiihtyneen kehitysvauhdin aiheuttaman sadon menetyksen, ja lähes aina sato nousee (Hakala 1998a, b).

Suurin hyöty kohonneesta hiilidioksidipitoisuudesta koituu kuitenkin kasveille, joiden kehitys ei ole sidottu lämpösummaan. Tällaisia ovat esim. nurmet, joiden sato MTT:llä tehdyissä tutkimuksissa lisääntyi reippaasti jo kun kasvukauden pituutta ja lämpötilaa lisättiin. Sadon lisäys oli vielä suurempaa, kun kohonneeseen lämpötilaan yhdistettiin hiilidioksidilisäys (Hakala ja Mela 1996). Myös juurisatokasvit hyötyvät enemmän hiilidioksiditason nostosta kuin esim. viljat, sillä ne voivat kasvattaa juurten kokoa periaatteessa rajattomasti. Viljoilla hiilidioksidin lisäys saattaa lisätä versomista ja siten jyvien lukumäärää alaa kohti, mutta jyvien koon on todettu lisääntyvän vain vähän hiilidioksiditason noustessa. Suurin hyöty ilmastonmuutoksesta Suomen kasvintuotannolle syntyy kuitenkin kasvukauden pitenemisen myötä käyttöön otettavista uusista ja satoisammista viljelykasvilajeista ja -lajikkeista, kuten aiemmin todettu rypsin korvautuminen rapsilla (PeltonenSainio ym. 2008a ja b).

\section{Ilmaston lämmetessä epävarmuus kasvaa myös Suomen kasvintuotannossa}

Vaikka Suomen osalta kasvintuotannon edellytykset yleisesti paranevat ilmastonmuutoksen seurauksena, viljelijöiden nettotulon kasvua tulevat todennäköisesti tulevaisuudessa vähentämään lisääntyneet kasvinsuojelukustannukset. Jo nyt on esimerkkejä kasvitautien lisääntymisestä ja uusista kasvitaudeista ja tuholaisista, jotka ovat alkaneet esiintyä Suomessa ilmaston lämmettyä (Hannukkala ym. 2007). Jatkossa leudommat talvet ja pidempi kasvukausi voivat johtaa tautien ja tuholaisten parempaan talvehtimiseen ja useampiin sukupolviin vuodessa ja siten tehokkaampaan lisääntymiseen (Carter ym. 1996). Myös ilmavirtojen mukana voi Suomeen saapua yhä useammin tuholaisia meitä eteläisemmiltä alueilta, ja niistä yhä useampi laji saattaa myös jäädä pysyvästi Suomeen. Esimerkkinä tällaisesta muuttajasta on koloradokuoriainen, joka on jo pysyvästi Suomeen asettunut tuholainen.

Kohonnut lämpötila lisää maan mikrobitoimintaa. Tämä voi johtaa maan eloperäisen aineksen vähentymiseen ja kiihtyvään ravinteiden mineralisoitumiseen, joka yhdistettynä suurempaan sademäärään etenkin kasvukauden ulkopuolella voi johtaa lisääntyneeseen ravinteiden huuhtoutumiseen ja eroosioon (IPCC 2007b, Hildén ym. 2005). Samoin tauti- ja tuholaisongelmien ja niitä seuraavien kasvinsuojelutoimenpiteiden vuoksi kasvinsuojeluaineiden huuhtoutuminen vesistöihin on vaarassa lisääntyä. Maatalouden ympäristönsuojelu tuleekin jatkossa yhä tärkeämmäksi. 
Leudontuneesta talvesta huolimatta kasvien talvehtiminen voi vaikeutua, jos kasvit ovat ilman suojaavaa lumipeitettä pakkasjaksojen aikana tai jos pellon pinnalle syntyy jääpeite sateen ja pakkasen vuorotellessa. Talven lämpimien ja pakkasjaksojen vuorottelu voi johtaa suuriin tuhoihin varsinkin puutarhataloudessa, jos kasvien dormanssi purkautuu, kasvuunlähtö käynnistyy ja sen jälkeinen pakkaskausi tuhoaa uuden kasvun. Näin tapahtui esim. vuoden 2007 keväällä Etelä-Suomessa, seurauksena joidenkin hedelmä- ja marjakasvilajikkeiden sadonmenetys. Myös keväiset lämpimät kaudet maan kuitenkin ollessa vielä jäässä voivat aiheuttaa mm. kuivumistuhoja puutarhakasveilla. Talven vaihtelevat sääolot tulevat olemaan ongelmana Suomessa vielä pitkään, huolimatta ilmaston lämpenemisen tuomasta helpotuksesta joihinkin talvehtimisongelmiin.

\section{Sopeutumisen välttämättömyys}

Syysmuotoiset ja monivuotiset viljelykasvit sekä monivuotiset nurmet, ml. energiakasvit voivat auttaa estämään ilmastonmuutoksen mukanaan tuomaa lisääntynyttä eroosio- ja huuhtoumariskiä. Monivuotisten kasvien viljely myös säilyttää ja lisää maaperän humusta. Ajan mittaan syysmuotoisten kasvien käyttö tulee myös varmemmaksi talvien yhä leudontuessa. Monivuotisten kasvien viljely tasaa kevään työhuippuja ja näiden kasvien etuna on myös se, että ne voivat käyttää hyväkseen talven aikana maahan kertyneen kosteuden paremmin kuin kevätkylvöiset kasvit. Pelkät viljelykasvien valinnat eivät kuitenkaan riitä, vaan lisääntyneet talvisateet vaativat uutta teknologiaa pellon tiivistymisen ehkäisemiseksi ja veden pitämiseksi poissa pelloilta. Koska tulevaisuudessa ruoan tuotanto tulee vaikeutumaan kuivuuden koettelemissa maissa (IPCC 2007b), Suomen on jo nyt syytä panostaa tuotantovalmiuden säilyttämiseen ja sen ennakoivaan parantamiseen sekä maatalouden ympäristönsuojeluun, vastatakseen osaltaan globaalin maataloustuotteiden kysynnän kasvun tuomiin haasteisiin. Myös uusien kasvilajien viljelyyn sopeuttamiseen ja uusien lajikkeiden jalostukseen tulee panostaa entistä enemmän.

\section{Johtopäätökset}

Sääolojen kannalta Suomesta saattaa lähivuosikymmeninä tulla nykyisen Tanskan veroinen maataloustuottaja. Suomen tulo osaksi keskeisintä Euroopan vilja-aittaa riippuu kuitenkin Suomen maatalouden sopeutumiskyvystä, maailmankaupasta ja kasvintuotannon tuotteiden kysynnästä. Kasvintuotannon tuotteiden kysyntään vaikuttaa lähitulevaisuudessa vahvasti kasvintuotanto-olojen kehitys, ja toisaalta elintason nousu sekä bioenergiasektorin kehitys muualla maailmassa. Vaikka ilmastonmuutoksen haitoista koituu lisäkustannuksia tuotannolle, maatalouden kokonaiskannattavuus saattaa lisääntyä satojen nousun myötä.

\section{Kiitokset}

MSc. Jos Helmich laski Hollannin säädatasta tässä esityksessä Hollannin alueista käytetyt tunnusluvut, mistä kiitos.

\section{Kirjallisuus}

Carter, T.R., Saarikko, R.A. \& Niemi, K.J. 1996. Assessing the risks and uncertainties of regional crop potential under a changing climate in Finland. Agricultural and Food Science in Finland 5, 329-350.

Hakala, K. 1998a. Effect of climate change in the North on growth, yield formation and photosynthesis of spring wheat and meadow fescue. Doctoral thesis, 160 p. Annales Universitatis Turkuensis SER. AII, TOM. 110.

Hakala, K. 1998b. Growth and yield potential of spring wheat in a simulated changed climate with increased $\mathrm{CO}_{2}$ and higher temperature. European Journal of Agronomy 9: 41-52.

Hakala, K. \& Mela, T. 1996. The effects of prolonged exposure to elevated temperatures and elevated $\mathrm{CO}_{2}$ levels on the growth, yield and dry matter partitioning of field-sown meadow fescue (Festuca pratensis, cv. Kalevi). Agricultural and Food Science in Finland 5: 285-298.

Hannukkala, A., Kaukoranta, T., Lehtinen, A. \& Rahkonen, A. 2007. Late-blight epidemics on potato in Finland, 1933-2002; increased and earlier occurrence of epidemics associated with climate change and lack of rotation. Plant pathology 56, 1: 167-176.

Hildén, M., Lehtonen, H., Bärlund, I., Hakala, K., Kaukoranta, T. \& Tattari, S. 2005. The practice and process of adaptation in Finnish agriculture. FINADAPT Working Paper 5, Finnish Environment Institute Mimeographs 335, Helsinki, 28 pp.

IPCC 2000. Emissions Scenarios. Special Report of the Intergovernmental Panel on Climate Change. N. Nakicenovic and R. Swart (Eds.), Cambridge University Press, Cambridge, England, 570 pp. 
IPCC 2007a: Summary for Policymakers. In: Climate Change 2007: The Physical Science Basis. Contribution of Working Group I to the Fourth Assessment Report of the Intergovernmental Panel on Climate Change [Solomon, S., D. Qin, M. Manning, Z. Chen, M. Marquis, K.B. Averyt, M.Tignor and H.L. Miller (eds.)]. Cambridge University Press, Cambridge, United Kingdom and New York, NY, USA.

IPCC 2007b: Summary for Policymakers. In: Climate Change 2007: Impacts, Adaptation and Vulnerability. Contribution of Working Group II to the Fourth Assessment Report of the Intergovernmental Panel on Climate Change, M.L. Parry, O.F. Canziani, J.P. Palutikof, P.J. van der Linden and C.E. Hanson, Eds., Cambridge University Press, Cambridge, UK, 7-22.

Peltonen-Sainio, P., Hakala, K., Jauhiainen, L. \& Ruosteenoja, K. 2008a. Rapsi korvaa rypsin jo lähivuosikymmeninä ilmastonmuutoksen edetessä. Maataloustieteen Päivät 2008. www.smts.fi

Peltonen-Sainio, P., Hakala, K., Jauhiainen, L. \& Ruosteenoja, K. 2008b. Comparing Regional Risks in Producing Turnip Rape and Oilseed Rape. II Future with Impacts of Climate Change and Breeding. Manuscript. 